\title{
A TEORIA PÓS-COLONIALISTA EM UM REFERENCIAL AO ESTÁGIO NA EDUCAÇÃO INFANTIL
}

Claudionor Renato da Silva ${ }^{1}$

Viviane Drumond ${ }^{2}$

\section{RESUMO}

Práticas pós-colonialistas na educação infantil são práticas que se esperam tornarem-se efetivas, para além de um referencial, ou seja, abarquem uma concepção de profissionalidade que se inicie na formação inicial, em cursos de pedagogia, no componente curricular de Estágio. A pesquisa organiza reflexões sobre as práticas educativas estagiais com as crianças de 0 a 5 anos. Problematizando: quais práticas são evidenciadas no dia a dia das escolas de educação infantil? São de imposições adultas ou aquelas que valorizam e evidenciam as vozes e os corpos infantis? O referencial é a teoria póscolonialista na educação e o estágio, enquanto campo do conhecimento. A metodologia, de natureza qualitativa utiliza-se da pesquisa bibliográfica. Os resultados indicam que nas práticas estagiais há um distanciamento de uma proposta pós-colonialista; há uma centralidade na professora e uma reprodução do modelo de ensino fundamental, o que exige conhecimentos do referencial póscolonialista, numa perspectiva de inovação educacional.

Palavras-chave: Teoria Pós-Colonialista. Estágio. Educação Infantil.

1 Doutor em Educação Escolar (UNESP/FCLar). Professor da Universidade Federal de JataíUFJ. ORCID: https://orcid.org/0000-0003-1693-4804. E-mail: claudionorsil@gmail.com

2 Doutora em Educação (UNICAMP). Professora da Universidade Federal de Rondonópolis UFR.ORCID: https://orcid.org/0000-0003-3212-1213.Email: drumondviviane@gmail.com 


\section{THE POST-COLONIALIST THEORY IN A REFERENCE TO THE INTERNSHIP IN CHILD EDUCATION}

\section{ABSTRACT}

Postcolonialist practices in early childhood education are practices that are expected to become effective, in addition to a referential, that is, encompass a conception of professionalism that begins in initial formation, in pedagogy courses, in the curricular component of Internship. The research organizes reflections on the statistical educational practices with children from 0 to 5 years old. Problematizing: what practices are evident in the day-to-day of kindergarten schools? Are they from adult impositions or those that value and evidence voices and children's bodies? The referential is postcolonialist theory in education and the internship as a field of knowledge. The methodology, of a qualitative nature, is used in bibliographical research. The results indicate that in the statistical practices there is a distancing from a postcolonialist proposal; there is a centrality in the teacher and a reproduction of the model of fundamental education, which requires knowledge of the postcolonialist framework, in a perspective of educational innovation.

Keywords: Post-Colonialist Theory. Internship. Child Education.

\section{LA TEORÍA POST-COLONIALISTA EN UN REFERENCIAL A LA ETAPA EN LA EDUCACIÓN INFANTIL}

\section{RESUMEN}

Las prácticas post-colonialistas en la educación infantil son prácticas, que se esperan llegar a ser efectivas, además de un referencial, o sea, abarcar una concepción de profesionalidad que se inicie en la formación inicial, en cursos de pedagogía, en el componente curricular de Prácticas. La investigación organiza reflexiones sobre las prácticas educativas estacionarias con los niños de 0 a 5 años. Problematizando: ¿qué prácticas se evidencian en el día a día de las escuelas de educación infantil? ¿Son de imposiciones adultas o 
aquellas que valoran y evidencian las voces y los cuerpos infantiles? El referencial es la teoría post-colonialista en la educación y la prácticas, en cuanto campo del conocimiento. La metodología, de naturaleza cualitativa, se utiliza de la investigación bibliográfica. Los resultados indican que en las prácticas estacionarias hay un distanciamiento de una propuesta post-colonialista; hay una centralidad en la profesora y una reproducción del modelo de enseñanza fundamental, lo que exige conocimientos del referencial post-colonialista, en una perspectiva de innovación educativa.

Palabras clave: Teoría Post-Colonialista. Prácticas. Educación Infantil.

\section{INTRODUÇÃO}

Práticas pós-coloniais na educação infantil são práticas, que se esperam tornarem-se efetivas, para além de um referencial teórico, ou seja, abarquem uma concepção de profissionalidade que se inicie na formação inicial em cursos de pedagogia, no componente curricular Estágio da Educação Infantil (creche e pré-escola).

O artigo visa discutir e refletir sobre as práticas educativas com as crianças pequenas ( 0 a 5 anos) permeadas pela abordagem pós-colonialista em educação.

O problema pode ser anunciado da seguinte forma: quais práticas são evidenciadas no dia a dia do estágio dos estudantes de pedagogia em escolas de educação infantil, de forma que seja possível lançar um olhar analítico a partir da teoria pós-colonialista? Como se constituem estas práticas? São práticas de imposições adultas ou aquelas que valorizam e evidenciam as vozes e os corpos infantis, sua(s) cultura(s)? Práticas de interações criança-criança ou somente aquelas direcionadas pelo adulto docente?

Com foco nessa problemática, são apontadas duas referências fundamentais no artigo, na interconexão aos relatórios de estágio escolhidos como fonte de dados da pesquisa: a primeira é a dos estudos pós-colonialistas e a segunda, a fundamentação do estágio como campo do conhecimento e espaço de formação em pesquisa.

Há um esforço neste artigo em conceituar e definir a teoria pós-colonialista, dada sua importância na particularidade da 
educação infantil, sobretudo, na proposta de inovação educacional. Esse "esforço" preenche uma lacuna nos textos sobre o tema que não aprofundam aspectos epistemológicos e orientações de referenciais sobre a teoria pós-colonial.

Objetiva-se, por meio da metodologia da pesquisa bibliográfica (SAMPIERI; FERNÁNDEZ-COLLADO; LUCIO, 2006) analisar relatórios de estágio, tendo por fundamentação analítica deste, a teoria pós-colonialista, buscando construir um elemento teórico formativo inovador para as práticas estagiais.

Os relatórios de estágios analisados são o produto textual de acadêmicos(as) de dois cursos de pedagogia de uma universidade federal do norte do Brasil, no interior do componente curricular Estágio da Educação Infantil, escritos entre os anos de 2015 a 2017 e que compõem um banco de dados para pesquisa no interior deste componente curricular nesta universidade.

Pretende-se que o artigo seja um referencial tanto para a formação inicial quanto para a formação continuada de professores(as) para e na educação infantil, bem como, para coordenadores e gestores da escola da infância, no sentido de serem pensadas novas ou outras práticas de educação para crianças pequenas ( 0 a 5 anos).

Um dos destaques da pesquisa é a terminologia póscolonialista, em que se entende que afirmar um "pós" é afirmar que não existe mais um (possível) colonialismo, mas assumimos a perspectiva que o processo do pós-colonialismo é um processo iniciado, mas não acabado - por isto, o termo pós-colonial é colocado em suspenso, pois o mesmo denota um processo finalizado que, em hipótese, não se acredita que as práticas em educação infantil tenham superado o caráter colonialista do cuidado, da supervisão e da vigilância das crianças pequenas, seus corpos, suas culturas, suas produções. Mas a pesquisa, em seu referencial busca avançar na discussão, ainda que breve, da teoria pós-colonial de oposição, proposta por Santos $(2004,2011)$ e que encontra ecos também em outra obra do autor de 1999.

Assim, que a máxima, e a premissa que é encaminhada, e permeia o artigo é que descoloniza-se a prática quando se descoloniza o pensamento. Pensa-se isto para a concepção de 
educação professoral dos que trabalham na escola da infância, deslocando o elemento "clássico" da didática voltada para o ensino, para um outro patamar, em um processo dialético, vivenciado e evidenciado na práxis. Assim, a didática pode estar voltada para as relações que as crianças estabelecem entre elas e com os adultos nos espaços de educação infantil. O caminho inicial desta abordagem pós-colonialista, na proposta aqui defendida está na formação universitária, no componente "Estágio" dos cursos de pedagogia.

As seções deste artigo: na primeira seção se discute a base da teoria do pós-colonialista voltada para os espaços da escola da infância. A segunda seção trata do Estágio, como formação e pesquisa. Há uma seção breve sobre a metodologia aplicada em Sampieri, Fernández-Collado e Lucio (2006). Os resultados e discussão, parte central do artigo, procuram uma análise crítica póscolonialista em excertos de Relatórios de Estágio. Nas considerações finais procura-se responder à problemática destacada e reforçar a máxima da pesquisa, aquela que assume a afirmativa de que se descoloniza a prática quando se descoloniza o pensamento, em que, o caminho inicial desta "descolonialidade" está na formação inicial, no estágio como componente formativo em cursos de pedagogia.

\section{SOBRE A ABORDAGEM PÓS-COLONIALISTA - O QUE SE CONSIDERA COMO PRÁTICAS PÓS-COLONIALISTAS EM EDUCAÇÃO INFANTIL?}

O termo pós-colonial nasce de uma perspectiva crítica nos anos 1970, mas só toma forma no campo acadêmico nos anos 1980, na obra "The empire writes back", escrito por Bill Aschcroft, Garet Griffths e Helen Tiffin, publicado em 1989.

A obra "The empire writes back" busca utilizar o termo póscolonial na literatura, inaugurando assim, uma teoria, um campo de pesquisa, de natureza crítica, no qual o prefixo "pós" traz todo um significado. Talvez, o principal, é a influência colonial que perpassa os sistemas sociais, reproduzindo ações e pensamentos que se esperavam "ultrapassados". 
A literatura, segundo esses autores, permite que se evidencie a percepção dos colonizados na produção escrita, não mais em marcas do pensamento ou do sentimento. E não só a escrita: a percepção dos colonizados se expressa, enfim, na arte, como um todo, seja na arquitetura, na música, na dança.

O termo que une o colonial com o pós-colonial, na proposição dos autores é "cultura", uma cultura dinâmica e que por isto, precisa ser estuda em sua gênese, constituição e efeitos na sociedade contemporânea (ASCHCROFT; GRIFFTHS; TIFFIN, 1989).

O termo pós-colonial, pós-colonialismo, não é um consenso (MATA, 2014) e está em "suspenso" por críticas postas por Boaventura de Sousa Santos, por exemplo, e que serão mencionadas, a seguir - surgem as terminologias, por exemplo, de coloniais que se caracterizam pelo posicionamento de que "pós" indicaria superação do colonialismo e, contudo, mesmo sem as "garras" da colonização e do colonizador, marcas e "jeitos" coloniais ainda permanecem nas dinâmicas sociais, nas produções de conhecimentos científicos, enfim como bem apontam Aschcroft, Griffths e Tiffin (1989).

Os elementos-chave do pós-colonialismo aplicado à literatura, na opinião de Aschcroft, Griffths e Tiffin (1989) são hegemonia; linguagem (idioma); lugar e deslocamento.

Para Césaire (2010) a luta e a crítica colonialista são na perspectiva destrutiva da figura do colonizador, ou seja, "descivilizar" o colonizador; fazer emergir ou desterrar seus instintos que se traduzem no racismo, na violência e no relativismo moral, sobretudo.

Boaventura de Sousa Santos (1999, 2004, 2011) destaca também a violência como um dos elementos-chave que caracterizam o colonialismo. Outro elemento é a questão da "exterioridade". $\mathrm{Na}$ teoria do pós-colonialismo, a exterioridade se volta às vítimas do colonialismo europeu;

à associação colonizado/excluído/discriminado e às imagens impostas pelo colonizador/opressor.

Mas, Boaventura deixa claro sua posição quanto ao póscolonial. Ele propõe uma teoria pós-colonial de oposição, que não se restringe ao cultural (LANDER, 2005; RODRIGUES; MARTIN, 2014; SÍVERES, SANTOS, 2013). 
O pós-colonialismo tem um sentido para Boaventura: trata-se do vetor único das desigualdades (enquanto teoria e enquanto política) entre o Norte e o Sul no tocante. E, trata-se de uma construção imposta pelo colonialismo europeu - considerando sua diversidade, como será discutido logo adiante: um colonialismo que deixou de ser territorial-geográfica-política e incorporou o social, a mentalidade e a condução das políticas locais em todas as esferas sociais - por isto a problematização teórica em questionar se de fato o colonialismo acabou (SANTOS, 2004).

Logo, estamos num território de um colonialismo do saber e de ciência; um questionamento sobre quem produz o conhecimento e em que contexto. O capitalismo, a partir de suas formas de poder no patriarcado sustenta de alguma forma, os espaços de colonizados e colonizadores. Os seis espaços-tempos propostos por Santos (2004) exemplificam bem esta territorialidade de colonizados e colonizadores. Os seis espaços-tempos são: exploração, diferenciação desigual, feiticismo das mercadorias, dominação e troca global desigual. Esses conceitos nos permitem refletir sobre a abordagem pós-colonialista no âmbito social, que inclui, obviamente, o escolar.

Boaventura tenta propor outro viés às bases pós-colonialistas, caracteristicamente vinculadas aos estudos culturais e explica isto afirmando que somente este único viés da crítica ao colonizador limita a análise, no sentido de "[...] ocultar ou esquecer a materialidade das relações sociais e políticas que tornam possível, quando não exigem, a reprodução desses discursos, ideologias e práticas simbólicas." (2004, p. 25).

Concordamos com Boaventura que a presença de vertentes analíticas europeias "[...] contribui [...] para um certo desarme político destes estudos." (2004, p. 26). Em que medida? Na medida em que, sem querer, e invisivelmente, ao realizar a denúncia, não instaura o campo da resistência.

$\mathrm{Na}$ opinião de Boaventura, a relação de sustentação do capitalismo ao lado do colonialismo, não pode, na fonte de denúncia pós-colonial, ser apenas direcionada ou levada a culpa somente e tão somente ao colonialismo. Elas estão juntas na análise e não divorciadas, como realmente impõe a corrente pós-colonial. Isto se justifica, por exemplo, nas questões da diversidade sexual e o 
preconceito contra a mulher ou ao homossexual. Se partir da denúncia colonial e seus resquícios, ela é incompleta, pois ao seu lado está a necessidade da análise política (Direitos Humanos, por exemplo), no bojo do capitalismo e, considerando os seis elementos capitais que fortalecem o sistema (patriarcado, na exploração, na diferenciação desigual, no feiticismo das mercadorias, na dominação e na troca global desigual) as análises das bases pós-colonialistas, realmente estão a ponto de uma revisão - ideia também apontada por Mata (2014).

Outra crítica ao pós-colonial, provocada por Santos (2004): a Europa não é monolítica. A Europa não é um todo e as formas de colonização, por exemplo, inglesa e francesa e, mesmo a portuguesa assumiram características diversas. A palavra-chave que conclui os apontamentos de Boaventura de Sousa Santos (2004) é emancipação, "emancipação social" que, segundo o autor, deve ser reinventada.

Em "A crítica da razão indolente: contra o desperdício da experiência" (SANTOS, 2011), emancipação está ligada ao conhecimento. E aqui se inicia nossa primeira aproximação deste quadro teórico com a educação e as práticas pedagógicas na educação infantil. Trata-se de uma proposta conceitual que Santos (2011) denomina de "conhecimento-emancipação".

A proposta de Santos (2011) é a saída da ordem, representada pelo colonialismo para uma nova ordem (que está no caos) representado pelo estágio do saber. Trata-se da primazia do conhecimento-emancipação sobre o conhecimento regulatório. Para o campo educacional, isto faz muito sentido.

Em Quijano (2005) encontramos uma aproximação à emancipação proposta por Boaventura de Sousa Santos que são aplicáveis à educação e à educação infantil. Trata-se do debate sobre os corpos - uma das dimensões necessárias que exigem novos posicionamentos no campo social, político, econômico e também educacional. Particularmente, na educação infantil, este aspecto, o corpo dual, aquele que deve aprender e noutro momento brincar, e ainda, em outro tempo-lugar realizar determinada ação, assume um debate central ao se estudar práticas educativas pós-coloniais.

Exige-se, na contemporaneidade, que o dualismo corpo/não corpo e seu "controle" estejam no centro de uma proposta de pensar 
e descentrar, na América Latina, uma "colonialidade de poder" travestida de eurocentrismo.

O não dualismo corpo/não corpo no viés do controle "didático" ou "docente" implicaria na evidenciação das culturas infantis e seus processos únicos, ao mesmo tempo, diversos de constituição na perspectiva pós-colonial.

"Pós" é mais do que um prefixo justaposto a um conceito e aplicável à educação. Como afirma Bhabha (1998), este conjunto indica um "além" que "[...] não é nem um novo horizonte, nem um abandono do passado." (p.19). É um estar na fronteira. Mas é um "além" do qual a educação e a educação infantil precisam acessar e só será possível"[...] se transformarem o presente em um lugar expandido e excêntrico de experiência e aquisição de poder." (p.23).

Ir além é também, segundo Bhabha (1998), um avanço rumo a mudança de paradigma e de realidade, de forma, a lançar um olhar para o presente e ver o que precisa ser mudado. Ou seja, não se vislumbra um futuro pós-colonialista sem uma séria análise do presente.

Práticas pós-coloniais na educação infantil são demarcadas por esta distância espacial do presente, implica estar "além" da fronteira, altera a "cultura" hegemônica, há deslocamentos, novos olhares; emerge quem esteve sempre impositivamente abaixo, silencioso, incólume. Desfaz as desigualdades e faz imperar a igualdade em seu sentido mais amplo possível, ou seja, se abrem caminhos mais pautados na democracia, na cidadania e na valorização das diversas culturas aí presentes, sobretudo as culturas infantis e produções das crianças.

\section{ESTÁGIO E FORMAÇÃO EM PESQUISA NA EDUCAÇÃO INFANTIL NUMA PERSPECTIVA PÓS-COLONIAL}

Os estudos pós-coloniais oferecem ferramentas analíticas para desvelar os vínculos estabelecidos entre a dominação epistemológica etnocêntrica e os conhecimentos sobre as crianças e sua educação vinculados nos cursos de formação inicial de professores(as). Instigando-nos a descontruir os postulados coloniais 
que produzem imagens distorcidas de povos e sujeitos. "A descolonização é, na verdade, a produção de espaços para os/as novos/as protagonistas sociais subalternizados/as pela colonização." (FARIA et al. 2015, p. 13). A criança é um sujeito histórico, participante ativa da construção da realidade social, produto e produtora de cultura, criadora de conhecimentos e saberes. Ela não é um "vir a ser" como afirmou Fúlvia Rosemberg (1976), ela é protagonista do seu conhecimento. O que se impõe para pensar infâncias autônomas e descolonizadas? Como produzir pedagogias descolonizadoras onde as crianças são o centro do processo?

Nos estágios nas instituições de Educação Infantil, observamos que os(as) professores/as com formação voltada para a escola de Ensino Fundamental acabam usando esses mesmos conhecimentos didáticos e metodológicos na educação das crianças pequenas, por receio de não saber fazer diferente do que aprenderam nos cursos de formação inicial de professores/as. Mas, o/a professor/a de Educação Infantil não dá aulas, não é um professor de disciplinas escolares, mas, sim, um/a professor/a de crianças que organiza o tempo e o espaço da Educação Infantil.

Este estudo destaca a importância de uma pedagogia centrada na criança, e as experiências com os estágios confirmam essa ênfase. Isso não apenas instiga à busca por uma educação das crianças pequenas na "forma-Educação Infantil" (FREITAS, 2007), mas também indica a necessidade de uma profunda revisão dos conhecimentos que são discutidos na formação de professores/as de crianças pequenas. Na Educação Infantil, o que deve estar em evidência é o protagonismo das crianças, e, desse modo, conteúdos formativos específicos devem ser contemplados nos cursos de formação inicial de professores/as de creche e pré-escola.

Para construir referências teóricas e metodológicas para a docência na Educação Infantil, os estágios em creches e pré-escolas tomam os três protagonistas da Educação Infantil: as crianças, os/as professores/as e as famílias, tendo a criança como protagonista privilegiada, como referência na construção de saberes na formação de docentes. O estágio na Educação Infantil deve considerar as diversas relações presentes no cotidiano das instituições e não unicamente a relação entre o/a professor/a e as crianças. 
Assim, partimos do princípio de que os adultos não são os únicos que educam, e as crianças não são as únicas que aprendem: adultos e crianças, portanto, estão sendo educados nas relações que estabelecem entre eles. As crianças aprendem com os adultos, e os adultos, por sua vez, aprendem com as crianças. E, também, as crianças aprendem umas com as outras nos coletivos infantis.

Portanto, discutir a formação de professores(as) de educação infantil e os estágios implica em questionar os nossos saberes sobre as crianças e as infâncias e, assim, evitar uma educação colonizadora das culturas infantis. Mas, como romper com um modelo de educação colonizadora e promover práticas emancipatória na educação infantil? Como desconstruir práticas adultocêntricas na relação com as crianças?

O estágio mantém como sua principal finalidade a formação dos/as estudantes e, ao mesmo tempo, favorece a pesquisa e a inovação, torna-se ocasião para promover o saber pedagógico sobre a infância e a criança a partir de outras bases epistemológicas. Infantino (2013) discute o estágio como momento de interação entre o saber acadêmico e o saber produzido na prática, nas instituições de Educação Infantil, aborda a observação como metodologia de trabalho.

Para Mantovani e Perani (1999), observar é uma habilidade fundamental na formação dos/as professores/as, porque, observando, aprende-se cada vez mais sobre as crianças e cria-se motivação para realizar pesquisas, para interpretar em nível teórico as ações e as práticas educativas. A observação ajuda a identificar os temas de maior dificuldade no trabalho dos/as docentes da Educação Infantil, que serão a base para fundamentar hipóteses de trabalho e de pesquisa. Pela observação, o/a professor/a pode refletir sobre sua prática com as crianças.

Ao discutir a formação continuada nas instituições de Educação Infantil, Cipollone (1998, p. 122) diz que "[...] é exatamente na prática educacional que se colocaram em discussão teorias e formularam-se novas hipóteses". As experiências, por si sós, não produzem inovações, mas, a partir da reflexão sobre a prática educativa pode-se chegar a um projeto de educação infantil que tenha por base a pesquisa e a pedagogia. 
A pedagogia, como ciência da prática, cumpre o papel de sistematizar os conhecimentos a respeito das crianças; das práticas pedagógicas; da organização do tempo e do espaço nas instituições de Educação Infantil - conhecimentos produzidos no âmbito desse segmento da educação, no sentido de fundamentar a prática educativa e de ser o aporte para a formação e o profissionalismo dos/as docentes que trabalham na área em uma perspectiva emancipatória e descolonizadora.

\title{
METODOLOGIA E PROCEDIMENTOS
}

A metodologia empregada é o da pesquisa bibliográfica, segundo Sampieri, Fernández-Collado e Lucio (2006). A particularidade da pesquisa bibliográfica aplicada ao estudo sobre as práticas pós-colonialistas na educação infantil reside no fato de que

\begin{abstract}
Amplia o horizonte do estudo ou orienta o pesquisador para o enfoque do seu problema, evitando desvios da elaboração original. No caso de estudos qualitativos, nos quais não se pretende estabelecer o problema de estudo em primeiro lugar nem ficar centrado ou restrito a uma causa específica, o marco teórico pode servir para expandir nosso panorama e dar-nos ideias de como planejar a pesquisa a partir de vários outros pontos de vista. (SAMPIERI; FERNÁNDEZ-COLLADO; LUCIO, 2006, p. 53)
\end{abstract}

Outras duas possibilidades são apontadas pelos autores, para o uso da pesquisa bibliográfica, e que se encaixam à proposta deste artigo: primeiro, a pesquisa bibliográfica permite e encaminha possíveis hipóteses e afirmativas dentro de um dado campo de estudo; segundo, "[...] Inspira novas linhas e áreas de pesquisa." (SAMPIERI; FERNÁNDEZ-COLLADO; LUCIO, 2006, p. 53). O levantamento bibliográfico permitido por pesquisas desta natureza implica também documentos ou como denominam os autores, documentos são "fontes de informação".

No caso desta pesquisa sobre práticas pós-colonialistas, a fonte primária (direta) são Relatórios de Estágio realizados por 
estudantes de dois cursos de pedagogia de uma universidade federal do norte do Brasil. Estes documentos constituem-se na classificação de Sampieri, Fernández-Collado e Lucio (2006) em "[...] relatórios de associações, trabalhos apresentados em congressos ou seminários [...] (p. 53)".

Esses dados são fontes de primeira mão ao pesquisador/a que a partir da problemática da pesquisa olha para o seu "marco teórico" - os relatórios de estágio, por exemplo.

O objetivo do método da pesquisa bibliográfica é fornecer informações, dados à elaboração teórica de uma abordagem e, neste caso, a articulação entre o problema da pesquisa, o referencial teórico escolhido para ao debate e os objetivos, configuram-se como condição indispensável.

Sobre a referência teórica que será o "combustível" para a análise dos dados da fonte primária, os autores defendem que a bibliografia estrangeira utilizada pode trazer alguns bons benefícios ao pesquisador(a):

As fontes primárias da pesquisa, portanto, os relatórios de estágio são úteis para responder ao problema da pesquisa e se construir a análise a partir do referencial inicial que se consolida na análise dos relatórios, os dados. Foram acessados apenas os relatos observacionais, correspondente às 20 horas de acesso inicial ao espaço escolar da educação infantil, antes da regência, que corresponde à outras 30 horas de atividade-docência.

Os procedimentos da pesquisa foram o acesso aos Relatórios de Estágio produzidos entre 2015 e 2017 pelos estudantes do $7^{\circ}$ Período de dois cursos de Pedagogia de uma universidade federal do norte do país. Esses relatórios foram lidos na íntegra e destacados os excertos que tinham ligação com o referencial pós-colonialista, no sentido de ser respondida a questão da pesquisa, a problemática.

Os relatos (correspondentes à observação) foram transcritos e colocados sob a análise do referencial da abordagem póscolonialista afim de que fossem identificados, segundo a metodologia proposta, para além da estruturação aprofundada da abordagem pós-colonialista, bases referenciais que indicassem novos conceitos e encaminhamentos de outras vertentes de pesquisa e pontos de vista para investigações futuras. 


\section{EXCERTOS DE RELATÓRIOS DE ESTÁGIO: CONFIDÊNCIAS PARA UMA PROPOSTA PÓS-COLONIALISTA EM EDUCAÇÃO INFANTIL}

As práticas observadas e relatadas pelos estagiários(as) nas escolas de educação infantil, revelam, de modo geral, uma postura professoral, centrada na professora, reprodução do modelo da escola de ensino fundamental, uma educação colonizadora que não promove a emancipação e autonomia das crianças; lança uma primeira reflexão sob uma abordagem pós-colonialista, aqui adotada: até que ponto as práticas observadas como colonialistas podem ser assim classificadas se estas mesmas práticas são denominadas no campo educacional como práticas tradicionais?

No relato a seguir, temos a expressão de um estagiário que chama a atenção para uma análise sobre práticas pós-colonialistas na educação infantil. Trata-se de uma atividade de massinhas, seguido de uma "tentativa" para escreverem seus nomes numa folha.

Dando continuidade por alguns minutos à brincadeira com a massinha. Depois, a professora e a monitora recolheram as massinhas e foi distribuído na sala, folhas, para que cada aluno tentasse escrever seu nome. Em cada mesa estava colado o nome de cada um, então, a partir do exemplo, eles tentaram escrever seus nomes. Muitos acabaram apenas desenhando, outros tentaram escrever, mas como nesta idade os desenhos chamam mais a atenção deles, já era de se esperar que fizessem isto nas folhas. (Relatório 1)

Na expressão "já era de se esperar" indica uma concepção de colonialismo no que tange a um olhar detido nas desigualdades (SANTOS, 2004), voltado à potencialidade, além de demonstrar, no início do excerto, as decisões adultas quanto "a hora de fazer o quê".

Nos próximos excertos a "direcionalidade" dada à rotina, pela professora, exige uma reflexão fundamental à luz da proposta do 
conhecimento-emancipação e conhecimento-regulação apontados por Santos (2004). Vejamos o excerto, antes.

Depois a professora pediu para fazer uma roda, para que sentassem no chão, pois ela iria contar duas historinhas, que eram a de "Cachinhos Dourados" e "O pequeno polegar", histórias que as crianças já conheciam muito bem. Depois disso, ela pediu para que as crianças lavassem as mãos, pois estava na hora do lanche. Em seguida, pedindo que as crianças fizessem a oração e depois cantando a música "meu lanchinho". Depois do lanche, hora da recreação, brincamos de cantigas de roda, e depois a professora distribuiu brinquedos para todos. Finalizando, assim, as atividades, aguardando que a Van levassem todos. (Relatório 1)

O que se propõe discutir nesta questão da "direcionalidade" é se perguntar, até que ponto, não seria necessário, serem revistas, ou como afirmaria Santos (2004), serem "reinventadas" as práticas pedagógicas. "Inculcar" e impor cultura é violência; é outra "marca" sob a análise da abordagem pós-colonialista aqui organizada. Violência é uma herança do colonialismo (SANTOS, 2004; RODRIGUES, MARTíN, 2004).

O próximo excerto representa esta reflexão que reforça o colonialismo das práticas pedagógicas na educação infantil e a falta de protagonismo nas ações infantis, em que sempre são "direcionadas" pelos adultos docentes.

Uma criança me perguntou se eu era boazinha. Achei interessante e fiquei pensando o que era ser boazinha na concepção daquela criança. Eu não podia interromper a aula para ajudá-la sobre isso, mas disse: "sim, eu sou boazinha". A professora precisou sair para pegar uma caixa de material na secretaria e disse para todas as crianças abaixarem as cabeças e ficarem quietas até que ela chegasse. $E$ assim as crianças ficaram. A professora entregou para as crianças as atividades relacionadas ao alfabeto, em que elas tinham que identificar a primeira letra do nome e pintarem. Outra atividade era de cobrir o 
tracejado, além das atividades envolvendo música e conversas direcionadas. Neste dia pensei muito na palavra "sensibilidade". Não tem como desenvolver um trabalho com crianças na educação infantil, sem ter sensibilidade. É preciso escutá-las, ser sensivel à suas falas e choros, que representam uma tentativa de comunicar aos outros os seus sentimentos. (Relatório 2)

Os seis-espaços-tempo elencados por Santos (2004) parecem subsidiar as discussões acima abertas sobre o "controle" da sala e dos corpos infantis, por exemplo, exigindo o silêncio na sala de aula, abaixando as cabeças na mesa, etc. Os seis-espaços, são: 1) patriarcado - espaços de poder na família, espaços domésticos que também se aproximam muito da realidade escolar, mas na escola, quem manda é a mulher professora; 2) exploração; 3) diferenciação desigual; 4) feiticismo das mercadorias; 5) dominação e 6) troca global desigual. Os espaços-tempo são detalhados em "Pela mão de Alice" (SANTOS, 1999).

Destaca-se, sobretudo, o espaço-tempo "patriarcado", embora o espaço de dominação da criança, na educação infantil seja representado pela professora. Os espaço-tempo, ou espaços estruturais são formas de poder que preserva a desigualdade não só da "submissão" à professora, mas as desigualdades entre meninos e meninas.

Estes espaços-tempo serão retomados ao longo da análise, quando será tratada a questão da heteronormatividade e a ideia de "família perfeita" ou "ideal".

Reitera-se no excerto a seguir, marcas da violência, numa perspectiva pós-colonialista nas práticas pedagógicas; uma violência silenciosa e intencional, quase invisível.

A professora mantém todas as crianças sempre atentas às atividades que ela desenvolve. Ela conversa muito com as crianças; chama a atenção para o que ela está falando e procura não deixar as crianças dispersas. Ela utiliza como recurso de controle de sala a punição e a recompensa. Se as crianças não fazem as atividades, como devem, ficam brincando, sem dar importância à solicitação da 
professora, elas são punidas e demoram irem para o intervalo. Se as crianças realizam as atividades solicitadas, com cuidado, atenção, elas recebem uma massinha para brincar. Vejo isso como um meio que a professora usa para manter a disciplina na sala. São ao todo, 26 crianças [...]. Se ela não consegue manter a disciplina, uns fazem as atividades, outros não. (Relatório 2)

Uma regência de estágio que não se difere muito da rotina da professora regente. O que classificamos como: "imitação de regência colonizadora". Pois, não há conflitos, todas as crianças são obedientes e cumprem as determinações docentes.

Este conceito, originado da análise bibliográfica desta pesquisa (SAMPIERI; COLLADO; LÚCIO, 2006), impõe ser repensado o papel da formação e da relação teoria e prática. Perguntamo-nos, por exemplo, qual a contribuição da universidade na formação de professores/as de modo a superar tais práticas colonizadoras (controle, punição/violência, direitos)?

Este foi o penúltimo dia da minha regência. Como de costume fiz o acolhimento das crianças, porém, faltou água na escola, neste dia. E, como ninguém sabia disto, recebemos, mesmo assim, as crianças. Fomos para o café da manhã e, ao retornar, a professora começou a ligar para os pais irem buscar seus filhos. Organizei as crianças sentadas em dois grupos, em mesas, pois havia poucas crianças neste dia. Então, apliquei a atividade que havia preparado. [...] substitui por um desenho do morango, para elas colorirem. Porém, antes de começar a pintar perguntei se alguém conhecia e já tinha experimentado morango. Alguns responderam que sim, e outros, não. Em seguida começaram a pintar. Antes mesmo de terminar, alguns pais começaram a chegar e, então, cada um levou consigo o desenho para mostrar aos seus pais. (Relatório 3).

O aspecto da oração "universal" vale a pena ser discutido próximo excerto. A prática da oração ao iniciar as atividades do dia, antes do lanche e em outros momentos faz parte da rotina das 
instituições de educação infantil investigadas. Como um ritual "necessário" e "imprescindível" na educação de crianças pequenas, na opinião dos(as) professores(as) e dos próprios(as) estagiários(as). Todos os relatórios do banco de dados apresentam a oração, muito presente em todas as atividades das crianças. Cabe-nos problematizar à luz do estado laico brasileiro e como a religião esteve como um "braço" do colonizador, submetendo, primeiro os indígenas, depois os escravos africanos, a uma "dominação" da mente, do idioma, dos sentimentos e da cultura.

No quarto dia, a professora regente faltou, vindo então uma substituta que iniciou a aula rezando a oração universal (Pai Nosso). (Relatório 4).

Novamente a oração aparece. A oração nas práticas e rotinas da educação infantil nos leva a perguntar, se uma música infantil pode ser base para um saber ou um conhecimento, neste caso, aplicado à alfabetização de crianças e, dessa forma, mais uma vez, a evidência de uma prática colonialista, que se reproduz.

O horário da segunda-feira é de dinamização, mas esta semana foi trocado pelo horário da sexta-feira, a pedido da professora. A aula começa comigo, recebendo os alunos com a oração do Anjo da Guarda e cantando a música 'Erguei as mãos'. Levei as crianças ao pátio para fazer a oração do Pai Nosso e cantar o Hino Nacional junto com as outras turmas e também ver uma apresentação de um musical do maternal. Acabado este momento voltamos para a sala e cantei juntamente com os alunos a música do alfabeto da Xuxa, para ver se o grau de aprendizagem deles sobre o alfabeto estava ideal [...] (Relatório 5)

É possível observar no relato a centralidade adulta e a utilização de músicas que "mecanizam" o aprendizado da língua materna e todo um conjunto de ações centralizadoras e de cunho "idealizador" tanto religioso, quanto cultural, em termos de escolhas musicais. 
Com relação à temática da família foi observado nos relatórios de estágio, a afirmação da "família ideal" e também do heterossexismo, assim, reproduzido nas práticas docentes efetivadas na escola de educação infantil.

Depois de ajudá-los a terminar, iniciamos, então, a introdução do conteúdo "A família". Foi uma exposição muito interessante e produtiva, onde todos falaram. Em seguida, distribuímos uma fichinha que continha a imagem de uma família com pai, mãe, meninos e meninas, para serem contados em seguida. Logo depois, colei no caderno de cada um, a tarefa de casa, para que eles desenhassem a sua família. (Relatório 4)

As relações de gênero também estão presentes nos relatos.

[...] a professora pediu aos alunos para que fizessem duas filas: uma de meninos e outra de meninas. $A$ monitora auxilia os alunos e conduz até os banheiros, juntamente com a professora, para lavarem as mãos para fazer a refeição. Voltam para a sala, como saíram, em fila. Sentaram em seus lugares e, assim, como no dia anterior, a professora e a monitora entregam o lanche para aqueles que trouxeram de casa e os demais aguardam o da escola. Quando todos terminaram de lanchar, foram brincar na área externa da sala. (Relatório 4)

Sobre a família ideal e as relações de gênero, a proposta póscolonialista de Boaventura (SANTOS, 2004) pode ser traduzida também no paradigma regulação social/emancipação social. Todas estas questões vão além da prática, estão vinculadas à política, como o devem ser, pois afirma que:

A ênfase no reconhecimento da diferença sem uma ênfase comparável nas condições económicas, sociais e políticas que garantem a igualdade na diferença corre o risco de combinar denúncias radicais com a passividade prática ante as tarefas de resistência que impõem. Isto é tanto mais grave quanto é certo que nas condições do capitalismo 
global em que vivemos não há reconhecimento efectivo da diferença (racial, sexual, étnica, religiosa, etc.) sem redistribuição social. (SANTOS, 2004, p. 26)

Indícios de uma proposta pós-colonialista, portanto, é justamente, conciliar às práticas, reflexões e ações nos âmbitos políticos, mais amplos, e que estejam além do aspecto apenas pedagógico.

A categoria "a colonização da sala de aula" emerge na pesquisa, pois é recorrente nos relatos de observação e regência dos estagiários (as), dos estudantes de pedagogia, que os professores(as) "determinam" ou "conduzem" a prática pedagógica sob um viés do controle, que remete ao colonialismo ou ao conceito de "conhecimento-regulação" de Boaventura de Sousa Santos. Esta categoria está organizada nesta pesquisa, a partir das possibilidades abertas pela metodologia utilizada em Sampieri, Fernández-Collado e Lúcio (2006).

Elenca-se a categoria "a colonização da sala de aula" em que, se objetiva pensar que a sala de aula parece "funcionar" sob uma lógica de relação colonial dos processos educativos na escola de educação infantil. Se trata este aspecto da sala de aula na educação, porque é exatamente o que os Relatos observacionais e regenciais nos trazem, sob o referencial teórico construído, o referencial póscolonialista.

Entendemos a educação infantil como espaço amplo, diverso, mas, então, diante destas realidades, quais encaminhamentos podem ser pensados a partir da abordagem pós-colonialista como oposição aos relatos aqui expostos pelos estagiários(as)?

Esta categoria "a colonização da sala de aula" tem uma relação com o que Rodrigues e Martín (2014) chama de "modelo dominante de racionalidade" e que se caracteriza pela exclusão e desigualdade.

Segundo Santos (2011), o silenciamento e amortização dos corpos infantis, sobretudo pela "colonização" permanente é a explícita regulação que neutraliza qualquer identidade local e qualquer proposta de transformação social. Minam-se quaisquer possibilidades de emancipação; segundo Santos (2011, p. 57) "[...] enquanto a regulação se torna impossível, a emancipação torna-se impensável.". 
Destas considerações, a prática pós-colonialista na educação infantil deve ser um "reversor", a princípio, de pensamento e de práticas, que possam ser inovadoras desde a formação inicial em cursos de Pedagogia. E, uma vez, praticados no "reverso" se naturalizam em "realidades" curriculares e formativas na área da Educação Infantil.

\section{CONSIDERAÇÕES FINAIS}

A problemática da pesquisa é respondida na medida em que parte de um referencial pós-colonialista na literatura (ASCHCROFT; GRIFFTHS; TIFFIN, 1989) e se expande, primeiramente nos estudos da cultura - tradição pós-colonial na sociologia (LANDER, 2005) - e, em segundo lugar, nas ideias da "teoria pós-colonial de oposição" (SANTOS, 2004, 2011); a problemática das práticas pedagógicas estagiais na educação infantil são, desta forma, postas em análise e abrem um campo de investigações nos cursos de Pedagogia.

A máxima construída sobre a prática, pauta-se, então, em uma perspectiva emancipatória, desde sua origem conceitual, na literatura; coloca-se contra toda e qualquer racionalidade cognitiva e instrumentalizadora que, talvez, ainda possam permanecer, como que inatas, inflexíveis, nas práticas da educação infantil e nas práticas formativas dos estagiários (as).

Algumas conclusões desta pesquisa e alguns encaminhamentos para continuidade em novas investigações:

- Práticas pedagógicas pós-colonialistas na educação infantil devem ser pensadas, a partir da concepção teórica que a sustém; devem ainda ser buscadas, na realidade empírica, sobretudo nos estágios curriculares de observação e regência e, em certa medida, promovendo inovação educacional (inovação pedagógica, curricular e didática);

- O estágio considerado como formação e pesquisa, na busca de inovações pedagógicas, curriculares e didáticas: 1) com nova(s) concepções e práticas (concepções pós-colonialistas, que favoreçam uma 
pedagogia centrada na criança; crianças como protagonistas e sujeitos de conhecimentos, produtoras de cultura(s). 2) com planejamentos de projetos de pesquisa em estágio nos espaços escolares que se iniciem com as categorias conceituais originadas desta pesquisa: "colonização da sala de aula" e "imitação de regência colonizadora". Estas categorias originam algumas questões investigativas, como por exemplo: a) a educação infantil está restrita a uma sala de aula ou a espaços da escola da educação infantil? b) Qual o papel dos formadores de formadores, sobretudo os professores(as) de Estágio diante destas categorias conceituais? Entendemos que o banco de dados de relatos de estágio, organizados no componente curricular dos dois cursos de pedagogia analisados, podem ser o ponto de partida para a temática aqui construída, somado aos relatórios de regência, que aqui ficaram de fora da análise e que nos convidam para uma discussão muito mais ampla, entre estagiários(as), docentes universitários e os docentes orientadores/formadores da escola estagial;

- Uma última contribuição da pesquisa, complementando o item anterior, é o apontamento da necessidade de formação inicial e continuada, sob a perspectiva pós-colonialista visando mudança de paradigmas, partindo de um enfoque nos(as) formadores(as) de formadores(as). Se admite, neste estudo, que as práticas pós-colonialistas se darão na interrelação universidade, estagiários(as) e a escola estagial; o estágio como formação e pesquisa exige dos docentes das disciplinas de estágio e, também das demais disciplinas, na universidade, sobretudo, maiores envolvimentos com a educação de crianças pequenas. 
Finalmente, compreende-se, que uma prática pós-colonialista tem a ver com criatividade e reinvenção das práticas, uma reinvenção, não apenas de pensar e propor, mas, efetivamente de aplicação e transformação em publicização, seja em periódicos, seja em livros ou capítulos de livros. Como afirma Boaventura (SANTOS, 2011), o caos enseja a transformação. O caos cria possibilidades, sonhos e projetos. $\mathrm{E}$, nesta aposta estão duas atividades que acredita-se, estarem à altura da educação e, particularmente, à educação infantil na perspectiva pós-colonialista: a primeira é um conjunto de atividades voltadas à análise 1) das diversas e múltiplas relações de poder no ambiente escolar, envolvendo os atores da escola, da família e da sociedade; 2) a abertura para processos políticos democráticos decisórios, respeitando as Diretrizes já postas oficialmente para a Educação Infantil e, 3) autonomia dos atores e respeito aos seus "empoderamentos" sociais atualizados e legais, em especial, na temática do empoderamento de meninas e mulheres (Agenda 2030 da ONU).

O segundo grupo de atividades apresentado na pesquisa (atividades de regência) se destaca como "mais importante" para as análises das práticas pedagógicas pós-colonialistas em estágio, pois sem este segundo grupo, o primeiro grupo de atividades (de observações) não desencadeará a transformação do "caos", pois, o observado é o que está acontecendo; no "praticado" espera-se as ações "descolonizadoras" ou "[...] uma reflexão centrada na promoção da criatividade da acção individual e colectiva." (SANTOS, 2011, p. 38).

A formação inicial e continuada de professores(as) como um trabalho investigativo e reflexivo sobre as práticas pedagógicas na educação infantil, no intuito de questionar e refletir acerca do trabalho docente com crianças pequenas busca, assim, na proposta deste artigo, descontruir práticas colonizadoras, que não dão voz às crianças e inibem suas manifestações e produções culturais ao impor a cultura hegemônica com práticas que reproduzem a sociedade racista, patriarcal, machista, homofóbica, que não respeita as diferenças e a diversidade dos sujeitos e, isso, desde a pequena infância. São ações que não apenas justificam as práticas colonialistas, mas substanciam teorizações para a construção metodológica de práticas pós-colonialistas. 
Espera-se, com o presente artigo, contribuir com reflexões às práticas pedagógicas da educação infantil, a partir do referencial póscolonialista, promovendo inovação educacional para um atendimento de qualidade às crianças pequenas na educação infantil.

\section{REFERÊNCIAS}

ASCHCROFT, B.; GRIFFTHS, G.; TIFFIN, H. The empire writes back: Theory and practice in post-colonial literatures. London: New Fetter Lane, 1989. DOI: https://doi.org/10.1177/089692059101800310. Acesso em 11 nov. 2020.

BHABHA, H. K. O local da cultura. Belo Horizonte, MG: Editora UFMG, 1998.

CÉSAIRE, A. Discurso sobre o colonialismo. Blumenau: Letras Contemporâneas, 2010.

CIPOLLONE, L. A atualização permanente nas creches. In: BONDIOLI, A.; MANTOVANI, S. (Org.). Manual de educação infantil de $\mathbf{0}$ a $\mathbf{3}$ anos. 9. ed. Porto Alegre: Artes Médicas. 1998, p. 121-139.

FARIA, A. L. G. et al. (Orgs.). Infâncias e pós-colonialismo:

pesquisas em busca de Pedagogias descolonizadoras. Campinas, SP: Leitura Crítica; Associação de Leitura do Brasil - ALB, 2015.

FREITAS, M. C. Prefácio: O coletivo infantil: o sentido da forma. In: FARIA, A.L. G. de (Org.). 0 coletivo infantil em creches e préescolas-falares e saberes. São Paulo: Cortez, 2007, p. 7-13.

INFANTINO, A. Estágio e formação na prática pedagógica em creches públicas italianas. Olhares, Guarulhos, SP. v. 1, n. 1, p. 7-39, maio 2013. Disponível em:

http://www.olhares.unifesp.br/index.php/olhares/article/view/8. Acesso em 11 nov. 2020.

LANDER, E. A colonialidade do saber: eurocentrismo e ciências sociais. Perspectivas latino-americanas. In: CLACSO. Ciências sociais: saberes coloniais e eurocêntricos. Buenos Aires, Clacso, 2005, p. 724. Disponível em: https://www.clacso.org.ar/libreria- 
latinoamericana/buscar_libro_detalle.php?id_libro=164. Acesso em 11 nov. 2020.

MANTOVANI, S. ; PERANI, R. Uma profissão a ser inventada: o educador da primeira infância. Pro-Posições, Campinas, v. 10, n. 1 (28), p. 75-98, mar. 1999. Disponível em:

https://periodicos.sbu.unicamp.br/ojs/index.php/proposic/article/vie w/8644101. Acesso em 11 nov. 2020.

MATA, I. Estudos pós-coloniais: desconstruindo genealogias eurocêntricas, Civitas, Porto Alegre, v. 14, n. 1, p. 27-42, jan./abr. 2014. Disponível em:

http://revistaseletronicas.pucrs.br/ojs/index.php/civitas/article/view/ 16185. Acesso em 11 nov. 2020.

QUIJANO, A. Colonialidade do poder, eurocentrismo e América Latina. In: CLACSO - Consejo Latinoamericano de Ciencias Sociales. A Colonialidade do saber: eurocentrismo e ciências sociais.

Perspectivas latino-americanas. Buenos Aires, Argentina: CLACSO, 2005, p. 117-142. Disponível em: https://www.clacso.org.ar/librerialatinoamericana/buscar_libro_detalle.php?id_libro=164. Acesso em 11 nov. 2020.

RODRIGUES, S. T.; MARTíN, N. B. Do pós-moderno ao pós-colonial: o constitucionalismo latino americano e novas intersubjetividades coletivas. Uma desconstrução do paradigma hegemônico da fundamentalidade dos direitos a partir da ética do outro. Revista Jurídica da UNIGRAN, Dourados, MS, v. 16, n. ${ }^{\circ} 32$, p.39-68, jul./dez., 2014. Disponível em: https://www.unigran.br/revista_juridica/ed_anteriores/32/artigos/arti go03.pdf. Acesso em 11 nov. 2020.

ROSEMBERG, Fúlvia. B. M. Educação para quem? Ciência e Cultura (SBPC), v. 28, n.12, p. 66-71, 1976.

SAMPIERI, R. H.; FERNÁNDEZ-COLLADO, C.; LUCIO, P. B.

Metodologia de Pesquisa. 3. ed. São Paulo: MacGraw-Hill, 2006.

SANTOS, B. S. A crítica da razão indolente: contra o desperdício da experiência. 8 ed. São Paulo: Cortez, 2011. v.1. 
SANTOS, B. S. Do pós-moderno ao pós-colonial. E para além de um e outro. 2004. Apresentado ao $8^{\circ}$ Congresso Luso-AfroBrasileiro de Ciências Sociais, Coimbra/ Portugal, 2004.

SANTOS, B. S. Pela mão de Alice. O social e o político na pósmodernidade. 7. ed. Porto, Portugal: Edições Afrontamento, 1999.

SÍVERES, L.; SANTOS, J. R. S. O conhecimento como princípio da colonialidade e da solidariedade. Conjectura: Filosofia e Educação, Caxias do Sul, v. 18, n. 3, p. 124-137, set./dez. 2013. Disponível em: http://www.ucs.br/etc/revistas/index.php/conjectura/article/view/19 28. Acesso em 11 nov. 2020.

Submetido em: Abril/ 2019.

Aceito em: Agosto/ 2019. 